Revisão 



\title{
Uma Revisão do Estado da Arte sobre a Aplicação de Aerogeradores de Pequeno Porte no Contexto das Redes Inteligentes
}

\section{A Review of the State of the Art on Small Wind Turbine Application in the Context of the Smart Grids}

\author{
Adeon Cecilio Pinto \\ Universidade Federal do Vale do São Francisco - UNIVASF, Juazeiro, BA \\ adeon.pinto@univasf.edu.br \\ Pedro José Santos Neto \\ Universidade Federal do Vale do São Francisco - UNIVASF, Juazeiro, BA \\ pedro_jsn@hotmail.com
}

Resumo: Após décadas de estagnação na maneira de distribuir energia elétrica, as redes inteligentes (smart grids) surgem como uma proposta inovadora, por meio de um sistema totalmente monitorado, garantindo benefícios para a distribuidora e, também, para o consumidor. Uma das grandes vantagens é a utilização da microgeração por parte dos consumidores, onde cada cliente poderá ter sua própria unidade geradora de energia complementar, a qual deve primar por fontes alternativas que preservem o meio ambiente. Nesse sentido, a energia eólica aparece como uma das mais eficientes, principalmente no Brasil, onde a matriz energética é composta basicamente por grandes hidroelétricas. Contudo, para alavancar a microgeração eólica, é necessário desenvolver a tecnologia de aerogeradores de pequeno porte. Esse tipo de aerogerador pode contribuir como uma das soluções para utilização de energia alternativa limpa e renovável adotada no conceito das smart grids, mas ainda esbarra na falta de pesquisas e na falta de incentivos governamentais nesse segmento. Este artigo visa mostrar o panorama das redes inteligentes e justificar o uso da energia eólica para geração em pequena escala, por meio de uma revisão do estado da arte da geração de energia eólica e de aerogeradores de pequeno porte, como uma vertente para a con-

Recebido em 17/09/2011 - Aceito em 15/04/2012.

\begin{tabular}{|c|c|c|c|c|c|}
\hline RECEN & 14(1) & p. $103-132$ & jan/jun & 2012 & DOI: 10.5777/RECEN.2012.01.07 \\
\hline
\end{tabular}


solidação da filosofia das redes inteligentes.

Palavras-chave: aerogeradores de pequeno porte; energia eólica; microgeração; redes inteligentes.

\begin{abstract}
After decades of stagnation on the way of distributing electrical energy, smart grids emerge as an innovative proposal by a fully monitored system, ensuring benefits to the utility as well as to consumers. A major advantage is the use of microgeneration by consumers, where each customer has his own generation of additional power which should excel in alternative sources that preserve the environment. In this sense, wind energy appears as one of the most efficient, especially in Brazil, where the power system is mainly composed of large hydroelectric generators. However, to use microgeneration from wind energy is necessary to develop the technology of small wind turbines. Such a wind turbines can contribute to the smart grid development, but it is impeded by a lack of research and government incentives in this area. This article aims to show smart grids review and justify the use of small scale wind energy generation, employing small scale wind turbines, as a way for consolidating the smart grids philosophy.
\end{abstract}

Key words: microgeneration; small wind turbines; smart grids; wind energy.

\title{
1 Introdução
}

A utilização de fontes renováveis de energia tem forte apelo devido à questão ambiental, visto que diversificar a matriz energética significa torná-la menos dependente das grandes hidroelétricas e também das usinas termoelétricas ou nucleares. A energia oriunda dos ventos configura-se como um tipo de energia bem diferenciada das demais e que tem alcançado resultados expressivos de crescimento, tanto em países desenvolvidos como em países emergentes, devido à sua natureza limpa e renovável, qualidades estas de suma importância no momento vivenciado, em relação à crise ambiental. Assim, sendo possível desenvolver sistemas de geração eólica de pequeno porte no Brasil, 
contribuir-se-á com o fortalecimento do setor elétrico, principalmente do setor de distribuição de energia, que ganhará em competitividade, uma vez que a energia utilizada servirá para aumentar e diversificar a produção energética outrora basicamente proveniente de grandes companhias ou grandes grupos (consórcios). Adicionalmente, esse sistema contribuirá com a preservação do planeta ao explorar um recurso natural abundante no país, em detrimento às fontes poluentes convencionais baseadas na utilização de combustíveis fósseis.

A utilização de pequenos aerogeradores tem ainda o importante papel social de levar energia elétrica às comunidades isoladas, onde a rede elétrica convencional não se faz presente. Desenvolvendo-se a tecnologia de geração eólica em pequena escala, pode-se suprir as necessidades desses brasileiros, devolvendo-lhes, além de melhores condições na qualidade de vida e trabalho, também, dignidade e igualdade das quais foram privados.

O desenvolvimento das redes inteligentes (smart grids) por sua vez, trará benefícios sociais e econômicos para o Brasil. A filosofia smart grid foi introduzida para expressar o conceito de rede elétrica inteligente. Esse conceito proporciona o fluxo de potência bidirecional na rede elétrica e a utilização de recursos computacionais para melhorar a eficiência, a confiabilidade e a segurança na geração, transmissão e distribuição de energia elétrica. Além disso, essa filosofia busca incorporar tecnologia de sensoriamento, de monitoramento e de telecomunicação para melhorar o desempenho da rede, identificando, de maneira antecipada, possíveis falhas e capacitando-a a se auto recompor diante de eventuais ocorrências que possam afetar sua performance [1, 2].

Nesse novo sistema, o consumidor passará a ser um componente ativo no processo de produção e distribuição de energia elétrica, podendo suprir suas necessidades de consumo e ainda comercializar o excedente. Esse fato aumentará a geração de renda das famílias e do próprio país, uma vez que não seriam necessários elevados investimentos no sistema de distribuição e/ou na geração, além de evitar transtornos como riscos de apagões ou sobrecargas no sistema elétrico.

O emprego de novas tecnologias deve ter como caráter prioritário, o desenvolvimento socioambiental, econômico e a eficiência energética. Dessa maneira, é funda- 
mental dominar a tecnologia de geração eólica em pequena escala atualmente disponível e ainda pouco aproveitada no Brasil, utilizando-a como um agente propulsor no desenvolvimento mútuo de outro conceito que surge como solução iminente para o sistema de distribuição de energia elétrica, que é a rede inteligente.

De acordo com o exposto, o objetivo primordial deste trabalho é fazer uma revisão detalhada do estado da arte sobre os aerogeradores de pequeno porte, considerando os aspectos necessários para a interligação dos mesmos à rede elétrica convencional. Além disso, será abordada a evolução das redes inteligentes no país e no mundo, trazendo conceitos relacionados à microgeração, com intuito de vincular essas duas tecnologias, uma vez que elas podem se complementar, diversificando a matriz energética e modernizando o sistema de distribuição de energia elétrica do país.

Considerando que a literatura técnica sobre essas duas temáticas mencionadas anteriormente é escassa, este documento visa estimular a disseminação das aplicações de pequenos aerogeradores operando como geradores distribuídos, motivando o desenvolvimento de pesquisas correlacionadas à utilização de fontes alternativas para microgeração, vislumbrando o futuro do sistema de distribuição e o fortalecimento das redes inteligentes.

\section{Redes inteligentes}

O aumento no consumo de energia elétrica levanta questionamentos sobre a eficiência do sistema de distribuição de energia do país. Além do crescimento na quantidade de energia consumida em relação à produção, a própria melhoria da condição socioeconômica da população ocorrida nos últimos anos fez com que a quantidade de equipamentos eletroeletrônicos aumentasse significativamente e, por consequência, elevasse o consumo de energia elétrica exigindo-se mais do sistema de potência. Apesar disso, a forma de se pensar a distribuição e o consumo de energia elétrica continuam ocorrendo da mesma forma daquela de décadas atrás. A atual evolução tecnológica e a utilização de dispositivos modernos não modificaram a maneira defasada de se distribuir a energia elétrica [3].

Por outro lado, recentemente, foi introduzido o conceito denominado de redes inteligentes (do inglês, smart grids), por meio da qual todo o sistema de distribui- 
ção estaria interligado e seria, permanentemente, monitorado em tempo real. Essas novas redes utilizam produtos e serviços inovadores em conjunto com um monitoramento inteligente, capaz de viabilizar a microgeração de energia elétrica através de fontes renováveis, em benefício do sistema elétrico. Além disso, será possível que o consumidor tenha o acompanhamento preciso sobre seu consumo residencial ou de qualquer outro estabelecimento industrial ou comercial, participando ativamente do processo de geração de energia através da microgeração e, podendo ainda, comercializar a produção excedente.

A comunicação entre o cliente e a concessionária será melhorada, uma vez que todas as informações serão compartilhadas e visualizadas em tempo real, assim, os produtos e serviços ofertados terão maior qualidade e poderão ser otimizados. Por conseguinte, as operadoras de energia terão maior controle sobre o sistema para garantir a eficiência energética, melhorando os níveis de qualidade do produto e provendo maior segurança no fornecimento de energia elétrica. Isso garantirá uma tomada de decisão mais rápida em resposta à ocorrência de falta, perturbação ou até mesmo o colapso no sistema, uma vez que o restabelecimento poderá ser feito a distância e de forma assistida.

Uma mudança primordial para adentrar neste novo cenário do sistema de distribuição será a substituição dos medidores de energia convencionais por equipamentos mais modernos e com maior número de funções. A utilização de novos medidores eletrônicos é o primeiro passo para se obter uma rede inteligente [4]. Estes devem incluir, além do consumo global de energia, leitura individual dos equipamentos domésticos, principalmente os "vilões" da conta de energia como chuveiro elétrico e ferro de passar. Será também função deste medidor quantificar a microgeração doméstica, considerando a energia gerada e a energia utilizada pelo consumidor, visto que haverá fluxo de potência bidirecional, ou seja, do sistema para o consumidor e do consumidor para o sistema elétrico.

Visando elucidar os comentários anteriores, a figura 1 apresenta um medidor eletrônico. Vale destacar que esses medidores digitais devem ser instalados em postes, dificultando as fraudes. Ao contrário do tradicional medidor analógico, o usuário terá instalado, em sua unidade consumidora, um mostrador no qual poderá acompa- 
nhar o consumo e ter uma estimativa do valor da conta mensal. Vale mencionar que existem alguns projetos pilotos em fase de testes, no Brasil, que têm como objetivo maior avaliar os benefícios alcançados com a instalação desse dispositivo.

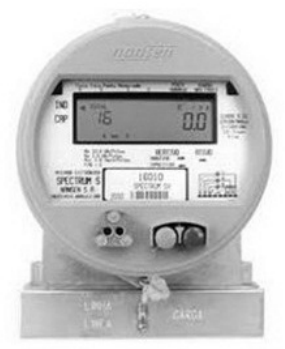

Figura 1. Medidor eletrônico [2]

A mudança das malhas atuais para as smart grids requer altos investimentos na aquisição e instalação de equipamentos e também em Pesquisa \& Desenvolvimento. Além disso, será preciso adequar as regulamentações para permitir uma série de novos serviços, como flexibilidade tarifária, escolha da fonte de energia geradora e o surgimento da cobrança antecipada, ou seja, a venda de energia por um modelo pré-pago de eletricidade. As companhias poderão oferecer novos planos de pagamento e ligar ou desligar o fornecimento sem a necessidade de deslocar um profissional até a unidade consumidora.

Para a consolidação dessa tecnologia, têm ocorrido discussões entre os profissionais da área de engenharia elétrica em diversos eventos técnico-científicos tradicionais. Além disso, têm-se criado, nos últimos anos, novos fóruns abordando exclusivamente este tema, dentre os quais se destacam: o Fórum Latino-Americano de Smart Grid, que teve a sua terceira edição realizada em agosto de 2009, na cidade de São Paulo, e o Smart Grid Latin America que faz parte de um evento maior chamado Metering, Billing/CRM Latin America [3].

Segundo Canazio [5], as primeiras experiências nacionais com rede inteligente serão feitas no Rio de Janeiro e em Minas Gerais para um grupo de dois mil consumidores, que poderão controlar o consumo de energia não apenas pelo medidor digital citado anteriormente, mas também pelo aparelho celular e pela televisão digital. Isso 
se deve a investimentos de duas empresas, a Light e a Cemig, que investirão cerca de $\mathrm{R} \$ 65$ milhões em um período de três anos. Essa iniciativa rendeu parceria com a Agência Americana para o Desenvolvimento e Comércio (U.S. Trade and Development Agency - USTDA), que culminará em um investimento total em torno de R $\$ 1$ milhão.

Nesse projeto mencionado, que já é considerado o maior da América Latina e um dos cinco maiores do mundo nesse setor, ainda será explorado o conceito de geração distribuída através da implantação de placas fotovoltaicas nas residências dos consumidores para obtenção das redes inteligentes com microgeração. A Agência Nacional de Energia Elétrica (ANEEL) acompanhará todas as etapas de desenvolvimento da pesquisa, começando pelo levantamento das questões legais e regulatórias que servirão de base para a implantação definitiva das redes inteligentes no Brasil [5].

\section{Microgeração}

O emprego da microgeração é uma das maneiras mais eficientes de aproveitar a malha elétrica do sistema de distribuição, principalmente, no que tange ao uso das fontes alternativas. Vale ressaltar que os sistemas de distribuição de energia elétrica no Brasil ainda não estão preparados para acomodar a geração distribuída.

Diante disso, mudanças significativas terão que ser efetuadas. Atualmente, os usuários de eletricidade, em geral, não participam do processo de geração de energia. Estes são apenas consumidores deste produto, ou seja, são elementos com um comportamento passivo frente ao sistema elétrico. O aumento da população e a melhoria das condições econômicas do país, principalmente nas últimas duas décadas, propiciaram uma elevação na demanda eletro-energética, o que evidentemente, apesar da estabilidade atual entre o consumo e a geração, poderá resultar em problemas futuros no fornecimento de energia, uma vez que o aumento da demanda não implica necessariamente o aumento de investimento em geração [6]. Outro fator importante a ser ressaltado, neste momento, é a dependência do Sistema Interligado Nacional (SIN) das condições climáticas, visto que, aproximadamente $74,9 \%$ da energia elétrica gerada no Brasil é oriunda de aproveitamentos hidrelétricos, de acordo com o Balanço Energético Nacional de 2011 [7]. Diante disso, a escassez de chuva por um longo pe- 
ríodo pode provocar um desequilíbrio entre a energia disponível e aquela necessária para atender ao sistema elétrico, conforme acontecera em 2001.

De maneira sucinta, a microgeração de energia pode ser definida como sendo a produção de energia elétrica por meio de pequenas instalações, ou seja, produção de energia em pequena escala, por empresas de outros setores produtivos, por comunidades, por indivíduos, usando alguns tipos de fontes primárias ou até mesmo processos não convencionais de conversão de energia ligados à rede de baixa tensão. $\mathrm{O}$ atual interesse demonstrado pelo aumento da produção de energia de origem renovável a partir de Produtores Independentes (PI) deve-se em muito à importância dada às questões ambientais nos dias atuais.

Uma grande vantagem dessa modalidade de geração é garantir o balanço entre a oferta e a demanda de energia elétrica, uma vez que a interligação da geração distribuída em pequena escala na rede elétrica caracterizará uma rede híbrida que permitirá que os sistemas de microgeração e produção em larga escala funcionem com uma maior eficiência energética e com menor custo que qualquer modalidade conseguiria em separado. Os problemas com os temidos "horários de pico", os quais ocorrem quando grande parte da população ativa retorna aos seus lares no final do dia e faz uso do chuveiro elétrico, iluminação e televisores, praticamente serão contornados, já que as concessionárias e os consumidores compartilharão juntos da produção da energia capaz de suprir esses picos de demanda e assim aliviar o sistema elétrico neste período de tempo.

Com a consolidação da geração distribuída em pequena escala, em um mercado comercializador liberado de energia elétrica, um novo modelo de geração deverá ser composto de geração centralizada e de microgeração diluída, com um grande número de pequenos e médios produtores de energia elétrica com tecnologia baseada, principalmente, em fontes renováveis integradas à rede elétrica. Dessa maneira, milhares de usuários terão sua própria geração tornando-se produtores e consumidores de energia, simultaneamente. O mercado de energia elétrica deverá fazer uso pleno de ambos, tanto os produtores de grandes blocos de energia quanto os pequenos produtores distribuídos [6].

A desverticalização do setor elétrico nacional, ocorrida nas últimas duas décadas, 
seguindo uma tendência mundial, tem contribuído para a liberação do mercado de energia elétrica, onde os grandes consumidores têm a oportunidade de escolher de quem comprar a energia, levando em consideração a relação preço/qualidade, além de outros fatores como imagem da empresa perante a sociedade. Nesse sentido, com o avanço das redes inteligentes, essa flexibilidade pertinente aos consumidores industriais também será estendida para todos os demais consumidores, independente da classificação, seja industrial, comercial ou residencial. Consequentemente, tais ações aumentarão a competitividade e estimularão a busca por melhores índices da qualidade do produto e dos serviços atrelados à energia elétrica.

Tecnicamente, uma instalação de microgeração é composta por um gerador de eletricidade que, prioritariamente, utiliza uma fonte alternativa como a eólica ou a solar, ao invés dos geradores movidos a combustíveis, amplamente utilizados nas zonas rurais brasileiras. Além disso, outros componentes utilizados nos sistemas de microgeração são o inversor de frequência, usado para efetuar a ligação à rede elétrica convencional, e um medidor de energia elétrica para quantificar a energia que é injetada no sistema elétrico, normalmente em baixa tensão. Neste momento, torna-se oportuno mencionar que o inversor compatibiliza a tensão produzida pelo gerador tanto em módulo quanto em frequência com aqueles valores da malha elétrica. Além da adequação, é necessário ter ciência de que a rede está susceptível à variações de potência conforme as solicitações da carga.

De forma a acompanhar essas oscilações, o inversor monitora continuamente a malha, ajustando os seus parâmetros de funcionamento. Assim, a energia depois de ajustada pelo inversor é injetada na rede após passar pelo medidor. Vale ressaltar que a instalação de microgeradores, geralmente, não faz uso de dispositivos de armazenamento como baterias, visto que não é necessário acumular energia, pois, para vender a eletricidade produzida, é necessária apenas a existência de uma conexão com a rede.

Os benefícios da microgeração conectada às redes de distribuição são inúmeros, além dos ganhos ambientais. A geração distribuída em pequena escala contribui positivamente para a redução das perdas técnicas, para o aumento dos perfis de tensão e ainda para a redução no carregamento do sistema de transmissão e/ou distribuição. Além disso, outro ponto extremamente favorável é o fato de a geração estar próxima 
dos locais de consumo, desse modo, não se necessita de maiores investimentos na estrutura de transmissão [8].

Assim, em uma sociedade cujo estilo de vida é fortemente dependente da energia elétrica, desenvolver tecnologias que permitam a geração e distribuição de forma eficiente e limpa, garantindo seu fornecimento ao longo do tempo com a máxima eficácia, é uma questão de extrema relevância.

Para que a energia elétrica gerada pelo consumidor seja injetada diretamente no sistema elétrico e tenha uma compensação na sua conta mensal, é necessário que haja uma interligação de maneira inteligente com o sistema elétrico. Pequenos produtores, quando estão interligados à rede de distribuição em baixa tensão, dão origem a um novo tipo de sistema de potência denominado Microredes, que podem operar em modo autônomo ou como parte da rede principal de energia elétrica [6]. Quando várias fontes são conectadas entre si e funcionam de forma conjunta e coordenada, dá-se origem ao que se denomina de plantas virtuais de geração.

A figura 2 retrata uma representação simplificada de como será a distribuição de energia elétrica com a inserção da microgeração. A energia produzida será injetada na malha elétrica somando-se àquela oriunda da geração convencional. Com isso, toda a energia deve ser monitorada para controle e supervisão dos próprios usuários e das concessionárias. As plantas virtuais de geração são operadas coletivamente por um órgão de controle centralizado, pois assumem a importância de uma planta convencional, podendo operar no mercado de energia elétrica [6].

Assim como nas redes inteligentes, nas microredes, toda a malha elétrica estará totalmente interligada de maneira que todas as informações sobre os fluxos de potência serão transmitidos de forma instantânea. Dessa maneira, os usuários poderão ter acesso ao uso da energia em suas próprias unidades consumidoras diretamente da internet. Com isso, o sistema elétrico integrará as infraestruturas, os processos, os componentes e as informações, de tal forma que a energia possa ser gerada, distribuída e consumida mais eficientemente e com custos reduzidos, possibilitando um sistema de energia mais seguro e confiável.

Como as microredes são compostas por fontes convencionais e não convencionais de energia, a energia eólica aparece como uma das mais promissoras para utilização 
em micro usinas. O setor deve dobrar de tamanho até 2015, movimentando US\$ 634 milhões anuais. No mundo, atualmente, há $50 \mathrm{MW}$ de potência gerada por aerogeradores de pequeno porte conectados à rede. Esse volume deve triplicar nos próximos quatro anos, alcançando $152 \mathrm{MW}$ [9].

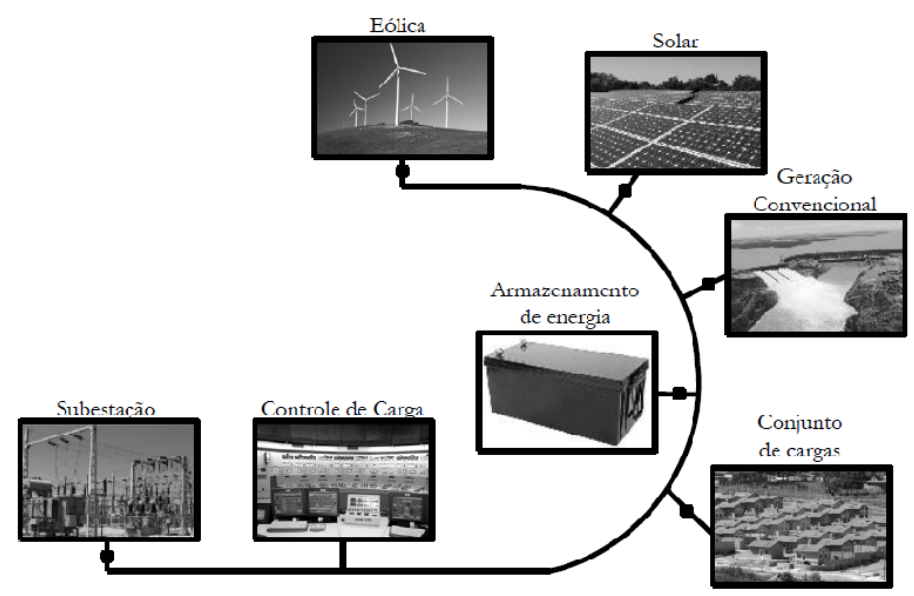

Figura 2. Microredes, adaptado de [6]

Em 2010, o mercado de microgeração eólica cresceu 26\% nos EUA, atingindo uma capacidade instalada de 25,6 MW. Foram vendidas 7,8 mil unidades de aerogeradores de pequeno porte, somando uma receita em torno de US\$ 139 milhões para os fornecedores, o que mostra a viabilidade econômica da produção de aerogeradores justificando o investimento nessa área. Outro fator importante é que, nos EUA, 90\% dos equipamentos de microgeração eólica estão conectados à rede [10].

No Brasil, a experiência em microgeração ainda está voltada para os sistemas isolados, sem conexão com a rede elétrica. Contudo, visando garantir e estimular o desenvolvimento da geração distribuída, a ANEEL apresentou uma proposta, em agosto de 2011, para regulamentar a microgeração conectada à rede elétrica convencional.

Nessa proposta, será criado um sistema de compensação de energia, próximo daquele almejado pelas redes inteligentes, mas ainda sem todos os aparatos de controle e de monitoramento garantidos pelas smart grids.

Esse sistema de compensação, porém, não prevê nenhuma transação financeira, ou seja, a produção excedente servirá apenas de bônus para compensação nas contas 
de energia subsequentes [11].

A título de classificação, serão considerados empreendimentos de microgeração aqueles cuja capacidade nominal é menor que $100 \mathrm{~kW}$, conectados à rede ou através de unidades consumidoras. Além disso, a ANEEL também pontua, na regulamentação citada anteriormente, que os geradores passíveis de registro sejam colocados como autoprodutores sem a contabilização direta na Câmara de Comercialização de Energia Elétrica (CCEE), o que poderá ser um benefício para o consumidor/produtor, uma vez que os gastos com o registro poderiam dificultar a adesão à microgeração [11].

O grande problema brasileiro ainda é a falta de investimentos. Apenas quatro empresas concentram a fabricação de aerogeradores de pequeno porte. Algumas universidades e centros de tecnologia estão tentando desenvolver novos protótipos, como é o caso da Universidade de São Paulo (USP) que desenvolveu, recentemente, um rotor 100\% nacional para turbinas eólicas de $10 \mathrm{~kW}$. A maior empresa nacional nesse segmento totaliza apenas 300 turbinas espalhadas pelo país, além de algumas parcerias firmadas com Universidades. Vale destacar também que os equipamentos importados, por sua vez, já totalizam 3 mil unidades no país [12].

\section{Energia eólica}

Energia eólica é a energia cinética contida nas massas de ar em movimento (vento). Seu aproveitamento ocorre por meio da conversão da energia cinética de translação em energia cinética de rotação, com o emprego das turbinas eólicas, também denominadas aerogeradores, para a geração de eletricidade, ou cataventos para trabalhos mecânicos como bombeamento d'água [13].

A utilização dos ventos para gerar eletricidade teve início no começo do século XX com os dinamarqueses. Logo após, os Estados Unidos, então, passaram a adotar a tecnologia dos "carregadores de vento", como eram conhecidos os primeiros aerogeradores. Essas máquinas eram capazes de fornecer até $1 \mathrm{~kW}$ de potência elétrica por meio da força motriz advinda do vento. Entre as décadas de 50 e 60, os alemães e os franceses contribuíram significativamente para o aumento da potência gerada por essas máquinas. Os franceses, por exemplo, construíram desenhos avançados dessas unidades geradoras com capacidade nominal entre $100 \mathrm{~kW}$ a $300 \mathrm{~kW}$ que acabaram 
sendo descartadas devido à pouca competitividade face às máquinas à combustão que utilizavam derivados de petróleo [14].

A primeira turbina eólica ligada à rede elétrica pública foi instalada em 1976, na Dinamarca. Atualmente, existem mais de 30 mil turbinas eólicas em operação no mundo. Nos Estados Unidos, a capacidade nominal dos aproveitamentos eólicos é da ordem de 4.600 MW instalados e com um crescimento anual em torno de $10 \%$. Estima-se que em 2020 , o mundo terá $12 \%$ da energia total gerada pelo vento, com uma capacidade instalada de mais de $1.200 \mathrm{GW}$ [15].

Uma das principais características que determinam a viabilidade da utilização da energia eólica em uma determinada localidade é o potencial eólico disponível naquela região. No estudo realizado pelo Centro de referência para Energia Solar e Eólica (CRESESB/CEPEL), onde surgiu o Atlas do potencial eólico brasileiro, estimou-se um potencial na ordem de $143 \mathrm{GW}$ [16]. Mas vale ressaltar que esse número é contestado por muitos estudiosos da área, visto que os dados de ventos ainda são preliminares, obtidos normalmente em baixas altitudes, incompatíveis com a altura das atuais torres. Nesse sentido, esse número pode ser muito maior.

Para transformar a energia cinética dos ventos em energia elétrica é necessário que a energia cinética seja transformada em movimento rotacional por meio das hélices da turbina. Através da equação (1) obtém-se a energia cinética de um escoamento de ar de massa $\mathrm{m}(\mathrm{kg})$, que se desloca a uma velocidade $\mathrm{v}(\mathrm{m} / \mathrm{s})$ [17].

$$
E_{c}=\frac{1}{2} m v^{2}
$$

Para ilustrar a energia disponível em um escoamento de ar, em conformidade com a expressão matemática apresentada anteriormente, a figura 3 apresenta o espaço relacionado com o rotor de uma turbina eólica de área $\mathrm{A}$, submetido a um vento incidente de velocidade $\mathrm{v}$ [18].

A potência é a taxa de variação da energia em um intervalo de tempo. Dividindose a equação (1) pelo intervalo de tempo, obtém-se a equação (2).

$$
P=\frac{m v^{2}}{2 \Delta t}
$$




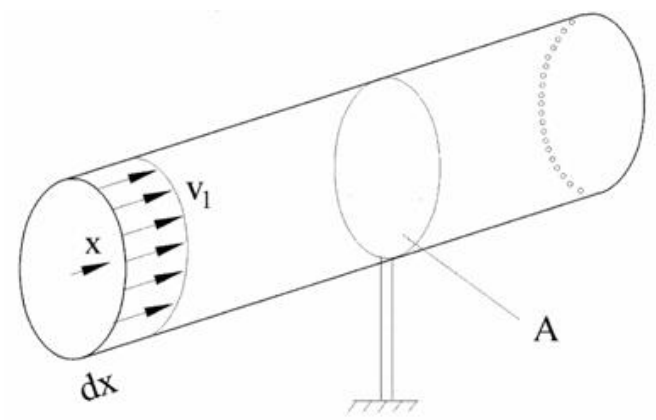

Figura 3. Fluxo de massa de ar

A coluna de ar, ao atravessar a seção transversal A $\left(m^{2}\right)$ varrida pelas pás da turbina, desloca uma massa de ar por unidade de tempo $(\mathrm{kg} / \mathrm{s})$, Conhecendo a densidade do $\operatorname{ar} \rho\left(\mathrm{kg} / \mathrm{m}^{3}\right)$ e a área de varredura do rotor, tem-se [17]:

$$
\frac{m}{t}=\rho A v
$$

A partir da energia disponível no vento, pode-se determinar a correspondente potência mecânica $P_{\text {disp }}(\mathrm{W})$, sendo essa proporcional ao cubo da velocidade do vento. Substituindo (3) em (2), obtém-se a equação (4).

$$
P_{\text {dis } p}=\frac{1}{2} \rho A v^{3}
$$

A equação (4) demonstra a grande influência da velocidade do vento na potência disponível num escoamento de ar. Contudo, apenas uma parcela da potência total disponível pode ser aproveitada para produzir trabalho, uma vez que o fluxo de ar, após passar pelas pás da turbina, ainda sai com uma velocidade menor que a incidente, porém não nula. Esse fato faz com que apenas uma parte da energia contida no escoamento possa ser aproveitada. Para levar em consideração esse fator de aproveitamento ou de rendimento, um coeficiente de potência $C_{p}$ é introduzido nos cálculos, representando uma fração da potência eólica disponível que é efetivamente aproveitada. Através dos estudos do físico alemão Albert Betz sobre escoamento de fluidos, realizados na década de 20, concluiu-se que a máxima potência teórica obtida por uma turbina eólica ocorre quando a velocidade do vento, após a passagem pelas pás, é de um terço da velocidade original. Assim, o máximo aproveitamento teórico da potên- 
cia disponível é cerca de 59\%, grandeza esta chamada de coeficiente de Betz.

Contudo, na prática, o rendimento das turbinas eólicas modernas não ultrapassa os $40 \%$ [18].

O rendimento efetivo na conversão numa turbina eólica, denominado fator de coeficiente de potência ou ainda rendimento aerodinâmico $C_{p}$, pode ser calculado pela equação (5), sendo $P_{m e c}$ a potência mecânica no eixo da turbina.

$$
C_{p}=\frac{P_{m e c}}{P_{\text {disp }}}
$$

Por fim, combinando as equações (4) e (5), obtém a equação (6), a qual permite determinar a potência mecânica desenvolvida no eixo da turbina [18].

$$
P_{m e c}=\frac{1}{2} \rho C_{p} A v^{3}
$$

Após discorrer sobre a conversão da energia cinética do vento e também sobre a formulação do cálculo da potência disponibilizada numa determinada massa de ar, na sequência, estão listados, em linhas gerais, os principais elementos constituintes de um sistema de geração eólica, além da fonte de energia primária que é o vento. São eles:

- Rotor eólico: composto pelo cubo e pelas pás, responsável pela conversão eletromecânica da energia.

- Caixa multiplicadora: responsável por transmitir a potência mecânica disponível no eixo do rotor ao gerador elétrico (carga). Este equipamento pode ser dispensável se o rotor estiver acoplado diretamente à máquina elétrica.

- Mecanismo de controle: responsável pela orientação do rotor eólico, controle de carga, velocidade e rotação, entre outros fatores de segurança e eficiência da turbina.

- Torre: responsável pela sustentação do aerogerador em determinada altura do solo, preestabelecida. 
- Sistema de armazenamento: composto, essencialmente, por baterias capazes de armazenar energia elétrica para o funcionamento de cargas com características ininterruptas.

- Elementos de ligação à rede: são componentes capazes de estabilizar o comportamento do aerogerador, moldando a energia produzida com os padrões da rede elétrica convencional.

Para se projetar um sistema eólico de uma determinada capacidade e para uma carga pré-fixada, supõe-se trabalhar no intervalo ótimo de rendimento do sistema com relação à curva de potência. Para tanto, torna-se necessário encontrar uma relação de multiplicação, de maneira que se tenha um bom acoplamento rotor/carga. É necessário, também, ter mecanismos de controle apropriados para melhorar o rendimento em outras velocidades de vento e aumentar o intervalo de funcionamento do complexo eólico.

O sistema de conversão eólico pode ser utilizado em três aplicações distintas. A primeira corresponde ao sistema isolado, geralmente em pequeno porte e dotada de dispositivos de armazenamento de energia. Esse armazenamento pode ser obtido pelo uso de baterias ou na forma de energia potencial gravitacional utilizada para bombeamento de água em reservatórios. Para o armazenamento em baterias, se faz necessário o uso de um dispositivo para controlar a carga e a descarga da bateria. O papel do controlador é proteger a bateria contra sobrecarga ou descargas elevadas. Vale destacar que, para alimentar equipamentos que trabalham em corrente alternada, (CA), utiliza-se um inversor de frequência.

A segunda aplicação é o sistema híbrido, onde há a combinação de duas ou mais fontes de energia, como geradores a diesel, placas fotovoltaicas, etc. Devido ao aumento da complexidade desses sistemas, faz-se necessária a otimização de cada fonte isoladamente. Esse tipo de arranjo é normalmente utilizado em aplicações de médio porte, para alcançar um número maior de usuários, justificando, assim, o investimento inicial elevado, característico dessa forma de aplicação.

Finalmente, a última aplicação consiste na interligação com a rede elétrica convencional. Esse formato não necessita de dispositivos de armazenamento e visa com- 
plementar os sistemas de grande porte pré-existentes. Para a interligação, é necessária a utilização de um inversor de frequência, capaz de tornar a energia produzida compatível em módulo e frequência com a energia da rede elétrica convencional. Esse é o modelo utilizado na microgeração e o seu desenvolvimento é fundamental para a consolidação das redes inteligentes. A figura 4 mostra os elementos de interligação do sistema eólico com a rede elétrica para a microgeração.

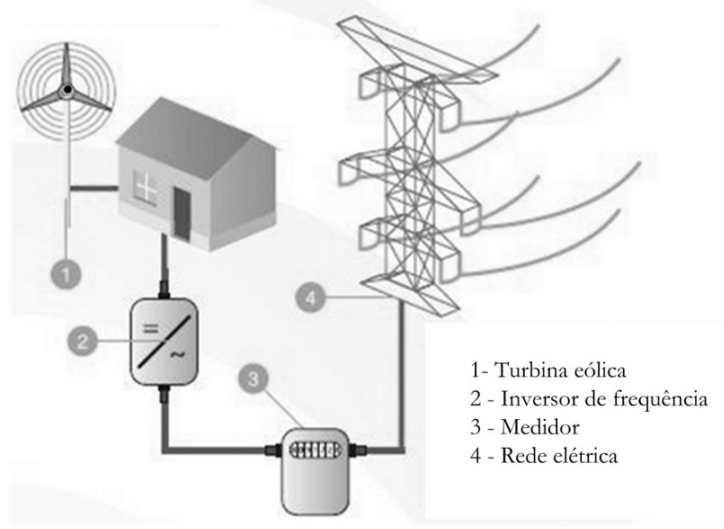

Figura 4. Sistema eólico conectado à rede elétrica, adaptado de [19]

Conforme mencionado, o maior problema desse modelo de utilização é a falta de tecnologia no setor. A maioria dos estudos é realizada para sistemas de grande porte, o que faz com que a tecnologia para geração eólica em pequena escala receba pouco incentivo e, consequentemente, os equipamentos integrantes do aerogerador apresentem custos elevados, principalmente a turbina eólica e o inversor de frequência.

\section{Aerogeradores}

Os aerogeradores podem ser classificados em três categorias principais de acordo com a potência nominal: aerogeradores de grande porte, com potência entre $500 \mathrm{~kW} \mathrm{a}$ $5 \mathrm{MW}$, normalmente empregados em arranjos com várias turbinas formando parques eólicos (wind farm) conectados à rede elétrica; médio porte, variando entre $100 \mathrm{~kW}$ a $500 \mathrm{~kW}$, podendo ser conectados à rede como fonte de geração distribuída ou em miniredes isoladas; e Aerogeradores de Pequeno Porte (AGPP), com potência entre 
$1 \mathrm{~W}$ a $100 \mathrm{~kW}$, utilizados principalmente em sistemas isolados, gerando eletricidade em locais remotos com condições favoráveis em relação à disponibilidade de ventos [20].

O rotor do aerogerador é composto pelas pás, eixo e engrenagens para a transmissão do movimento de rotação para o gerador elétrico. Quanto às pás, a grande maioria dos modelos atuais adota um número de três pás por máquina devido à relação custo/benefício da estrutura. Quanto maior o número de pás, maior o rendimento da turbina, porém aumenta-se o investimento do projeto, tornando inviável um modelo com um número superior a três devido aos custos e, inferior a três devido ao baixo rendimento. As pás interagem diretamente com as forças de sustentação e de arrasto do vento e seu desempenho aerodinâmico é essencial para a geração de eletricidade. Os modelos atuais possuem eixo horizontal de três pás, geralmente fabricadas de fibra de vidro, material leve e relativamente barato, capaz de resistir às intempéries e corrosões. Porém, alguns fabricantes de aerogeradores de pequeno porte utilizam a madeira para confecção das hélices [21].

Com relação à posição, o rotor pode estar a jusante (down wind) ou a montante (up wind) em relação à torre. No primeiro caso, a torre exerce pressão sobre as pás e, no segundo, são as pás que provocam esforços vibratórios na torre. Para utilização do sistema a montante, é necessário mecanismo que oriente o rotor perpendicularmente ao fluxo do vento, enquanto, no primeiro caso, esse processo é intrínseco dessa topologia, ou seja, dispensa o uso do dispositivo de alinhamento.

Conforme anteriormente mencionado, a área varrida pelo movimento circular das pás define a quantidade de energia captada pelo aerogerador. Portanto, a energia útil está diretamente ligada ao tamanho e ao ângulo de torção sobre o eixo longitudinal da pá. Enquanto o sistema de engrenagens transfere o movimento rotatório ao gerador elétrico, este funciona como um dínamo ou alternador. A torre de sustentação deve ser projetada em função da carga mecânica exercida pelos equipamentos suspensos, da força do vento que terá que suportar (força horizontal) e da vibração causada pelo movimento das pás [22].

Uma vez que há uma relação de proporcionalidade entre o fluxo de ar e a força de sustentação aerodinâmica, faz-se necessária a presença de um controlador de potência 
rápido e efetivo a fim de evitar sobrecarregamento elétrico e mecânico no sistema de transmissão e demais componentes do sistema eólico. Basicamente, existem dois tipos principais de controle aerodinâmico, o controle estol (stall) e o controle de passo (pitch).

A energia mecânica pode ser convertida em energia elétrica (e vice-versa) através das máquinas elétricas. Essas máquinas atuam como geradores ao converter a energia mecânica de rotação do seu eixo em energia elétrica, segundo a lei de Faraday da indução eletromagnética, que explica o fato que quando um condutor se move dentro de um campo estacionário, ou quando um campo varia sobre um condutor, ocorre uma indução de tensão elétrica sobre o mesmo.

Com o intuito de esclarecer melhor uma unidade de geração eólica, a figura 5 apresenta os elementos fundamentais de uma turbina eólica interligada à rede de distribuição, incluindo o gerador elétrico [13]. Os geradores elétricos utilizados em sistemas eólicos podem ser síncronos ou assíncronos. O gerador síncrono pode ter circuito de excitação independente ou utilizar ímãs permanentes para magnetização dos polos do rotor, como é o caso da maioria dos geradores de pequeno porte. Para regular a tensão gerada no gerador síncrono, basta monitorar a tensão de saída e efetuar o controle da corrente de excitação. O gerador assíncrono pode ter o rotor em gaiola de esquilo ou bobinado. As máquinas assíncronas são mais robustas, relativamente mais fáceis de construir e mais baratas. Além disso, possuem também alta relação potência/peso, porém para seu funcionamento, necessitam absorver reativos [23].

Quanto à interligação com a rede elétrica, podem-se dividir os geradores em quatro grupos. O gerador elétrico conectado diretamente à rede elétrica (velocidade fixa), normalmente, apresenta problemas relacionados com a qualidade da energia gerada, principalmente devido às variações de frequência e de tensão resultantes a quaisquer perturbações na fonte primária (vento). As variações na velocidade da turbina refletem diretamente na potência fornecida. Esses geradores podem ser síncronos ou assíncronos e são fabricados de forma simples, de baixa potência e com poucos polos nos rotores, necessitando, portanto, de caixas multiplicadoras de velocidade. O gerador síncrono exige uma operação sincronizada com a rede elétrica, não permitindo nenhuma regulação de velocidade. O gerador assíncrono permite uma pequena varia- 
ção de velocidade devido ao escorregamento, fazendo com que seu uso seja um pouco mais flexível, sendo também mais robusto e barato, além de não injetar componentes harmônicos no sistema.

A segunda classe é a de geradores conectados à rede elétrica através de conversores estáticos (velocidade variável). Esses conversores eletrônicos são utilizados para manter a frequência de saída fixa, independente da frequência do sinal gerado, isso é, desacoplando o aerogerador da rede elétrica. Caso haja perturbações na turbina, isto não é compartilhado com o sistema, em se tratando de frequência. Consequentemente, garante-se uma boa interação entre a central eólica e a malha elétrica.

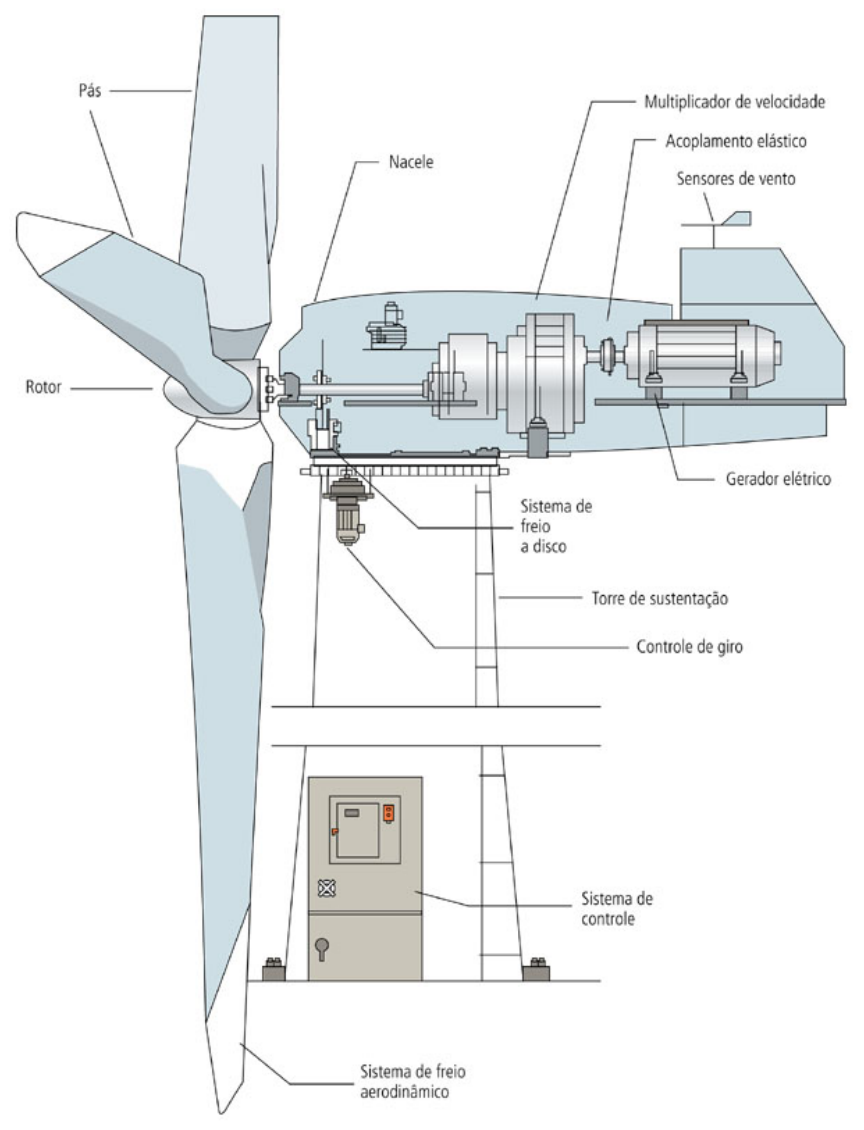

Figura 5. Modelo de aerogerador [13]

O gerador assíncrono, conectado diretamente à rede elétrica com rotor bobinado 
duplamente alimentado (velocidade variável), utiliza o controle de velocidade feito por um conversor conectado ao circuito do rotor. Essa configuração permite uma ampla faixa de regulação de velocidade, tanto abaixo quanto acima da velocidade nominal. Normalmente, são utilizados geradores de poucos polos, portanto, exigem-se os sistemas multiplicadores de velocidade. A favor dessa topologia versa a utilização de um inversor com capacidade nominal de aproximadamente $30 \%$ da potência nominal da turbina, visto que esse conversor está conectado ao rotor da máquina elétrica [18].

Por último, existe o gerador síncrono conectado à rede através de um conversor sem multiplicador de velocidade (velocidade variável). Nessa configuração, o gerador síncrono trifásico utiliza excitação independente ou rotor de ímã permanente (GSIP).

É importante ressaltar que esta configuração é amplamente utilizada em aerogeradores de pequeno porte. O gerador possui uma grande quantidade de polos, gerando em frequência baixa e variável, de acordo com a velocidade da turbina. A solução com ímãs permanentes apresenta maior rendimento, pois, praticamente, não tem perdas no rotor.

\subsection{Aerogeradores de pequeno porte (AGPP)}

Os aerogeradores de pequeno porte possuem potência entre $1 \mathrm{~kW}$ e $100 \mathrm{~kW}$ e são largamente utilizados no fornecimento de energia em sistemas isolados. Na aplicação isolada, o AGPP é o único responsável pelo fornecimento de energia elétrica ao consumidor. Para que o fornecimento seja contínuo e ininterrupto faz-se necessário o uso de dispositivos de armazenamento de energia.

Contudo, para microgeração é necessário interligar o aerogerador com a rede elétrica, utilizando, normalmente, o gerador síncrono de velocidade variável. O AGPP pode possuir gerador elétrico de corrente contínua sem escovas, de indução com rotor bobinado ou, mais comumente, gerador síncrono de ímã permanente (GSIP). Em sua topologia básica, a corrente alternada do GSIP é convertida em corrente contínua através de um retificador em ponte completa (ponte de Graetz) e, depois, em corrente alternada através de um inversor (Conversor CA/CC/CA). A figura 6 apresenta o diagrama de blocos do sistema AGPP conectado à rede elétrica. 


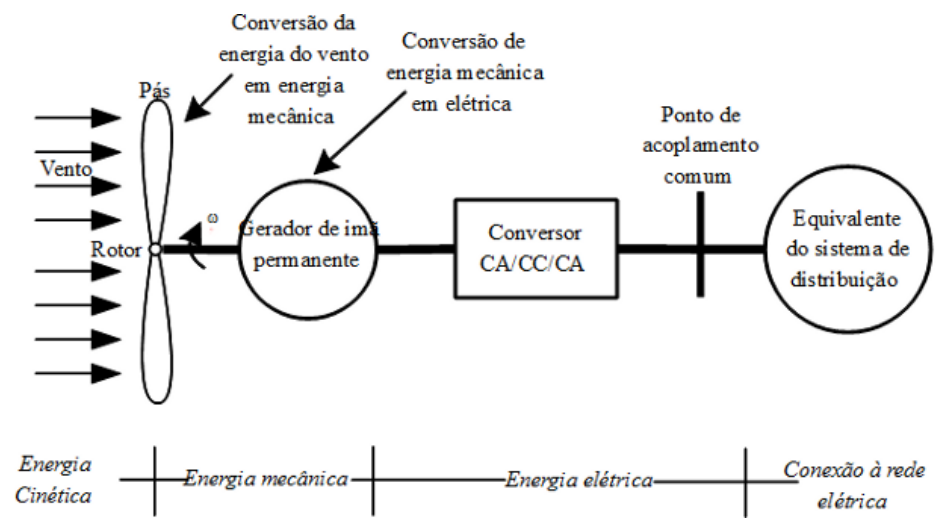

Figura 6. Diagrama de blocos da interligação do AGPP com a rede elétrica

O gerador síncrono de velocidade variável faz com que a tensão e a frequência de saída variem proporcionalmente à rotação do rotor eólico. Portanto, é necessário, utilizar um conversor para transformar a corrente alternada produzida no gerador em corrente contínua (CA/CC), visando efetuar o rastreamento da máxima potência da turbina. Graças aos avanços da eletrônica de potência, pode-se processar a energia elétrica através de conversor estático pelo qual é possível extrair a máxima energia disponível para cada velocidade do vento. O conversor CC/CA utiliza o sinal gerado na etapa anterior e o transforma novamente em alternada para a interconexão com a rede elétrica convencional [20].

A figura 7 , fornece uma visão mais detalhada do sistema de interligação do aerogerador.

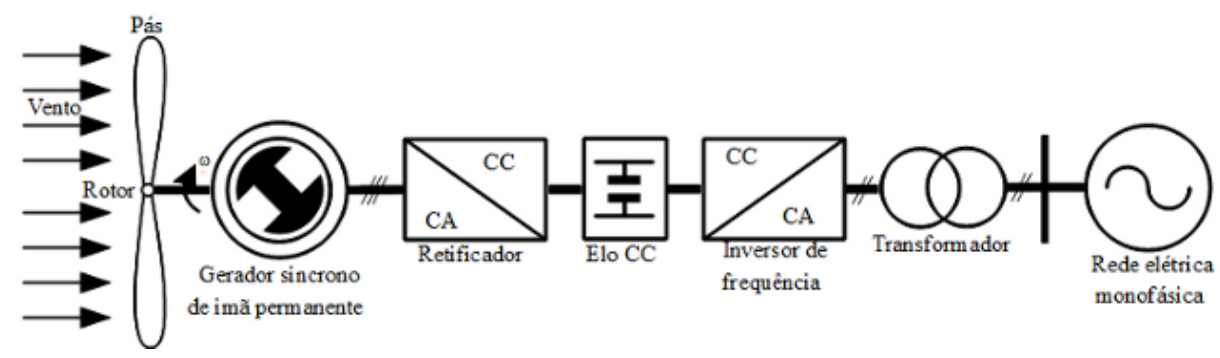

Figura 7. AGPP e demais componentes de interligação à rede elétrica

O elo CC faz parte do sistema de controle da tensão e da corrente do aparato eólico-elétrico, e o transformador elevador se faz necessário para ajustar a saída da 
tensão com o sinal da rede elétrica disponível para o consumidor. Os elementos que merecem destaque, além daqueles já mencionados, são o retificador (CA/CC) e o inversor de frequência (CC/CA), os quais desempenham papéis cruciais na interligação dos sistemas de microgeração e de geração convencional.

Um retificador trifásico em ponte completa é composto por três braços formados por dois diodos cada um. Esse equipamento converte a tensão CA do gerador em tensão CC. Contudo, como consequência da não linearidade característica da retificação por pontes a diodo, a forma de onda da tensão e da corrente elétrica no estator do GSIP não apresenta comportamentos senoidais, em vez disso aparecem sinais distorcidos com elevados conteúdos harmônicos. Os harmônicos de corrente e de tensão geram componentes assíncronos no campo magnético do entreferro, induzindo correntes parasitas no núcleo do rotor, causando problemas de perdas e de aumento na temperatura da máquina. Um método de correção desse problema seria a utilização de conversores denominados corretores do fator de potência, capazes de aproximar os sinais gerados daqueles senoidais [20].

Finalmente, analisando o inversor, o seu papel principal é garantir o fornecimento de energia elétrica com a qualidade necessária para que não se produza nenhuma degradação ou dano aos aparelhos ligados ao sistema. Em outras palavras, o equipamento tem a função de manter o funcionamento harmonioso entre o aerogerador e a rede convencional, em quaisquer circunstâncias. Dito isso, é necessário ainda dimensionar o inversor, o que deve ser feito de acordo com a potência nominal do sistema, o fator de demanda e a característica de operação das cargas.

Existem basicamente dois tipos de inversores disponíveis atualmente no mercado: aquele que produz onda senoidal modificada e o que produz onda senoidal pura. Via de regra, a diferença entre eles é mínima, mas pode ser significativa em certas aplicações, dependendo das cargas a serem alimentadas. O inversor de onda senoidal modificada pode alimentar, de maneira satisfatória, a maioria dos equipamentos e eletrodomésticos normalmente encontrados em uma residência convencional, além de apresentar um custo menor. O inversor de onda senoidal pura é projetado para fornecer energia de qualidade igual ou superior àquela fornecida pela concessionária de energia [24]. 
Para transferir a potência ativa gerada pelo pequeno aerogerador para a rede elétrica pode-se utilizar o inversor monofásico de onda completa ilustrado na figura 8 Vale destacar que o transformador eleva a tensão de saída para níveis adequados e ainda garante a isolação galvânica ao gerador eólico, tornando o sistema mais estável e seguro.

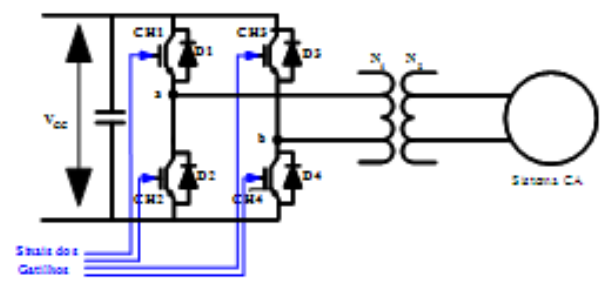

Figura 8. Inversor monofásico de onda completa

A maneira mais simples de gerar os pulsos de comando para as chaves estáticas ( $\mathrm{CH} 1, \mathrm{CH} 2, \mathrm{CH} 3$ e $\mathrm{CH} 4)$, diferenciado pelo nível de tensão nos pontos a e b da figura anterior, é aplicando a estratégia de chaveamento denominada de modulação PWM (Pulse Width Modulation), que se caracteriza por apresentar apenas dois níveis de tensão entre os pontos citados. A geração de comandos para as chaves é realizada comparando o sinal da onda moduladora (senóide) com o sinal da onda portadora (triangular). Um exemplo desse tipo de modulação é apresentado na figura 9, [24].
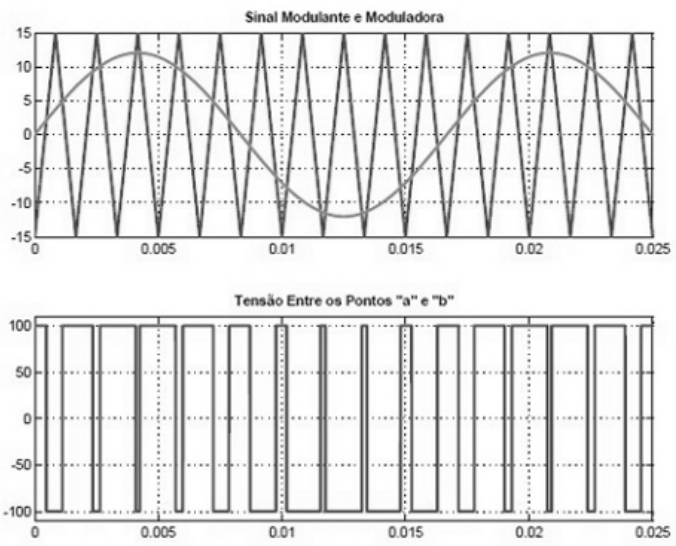

Figura 9. Modulação PWM 
A conexão de fontes de geração distribuída à rede elétrica é regulamentada, em âmbito internacional, pela norma IEEE 1547 - "Standard for Interconnecting Distributed Resources With Electrical Power Systems”, de 2003. Essa norma aborda as etapas que vão desde o projeto, a comercialização e as aplicações das fontes distribuídas de energia conectadas à rede elétrica [24,25]. Vale ressaltar alguns aspectos importantes dessa norma, tais como:

- Regulação de tensão: a fonte de geração distribuída deve ser capaz de manter a tensão no Ponto de Acoplamento Comum (PAC) dentro dos limites aceitáveis para a rede elétrica local.

- Perturbações de tensão: a unidade de geração distribuída deve ser dotada de sistemas de segurança que monitorem a magnitude da tensão e o ângulo de fase no PAC. Caso ocorra perturbação na rede, de forma que a tensão no PAC fique menor que $50 \%$ ou superior a $120 \%$ da tensão nominal, a fonte secundária deve ser desconectada em até 0,16 s, que é o chamado Tempo de Seccionamento (TS).

- Perturbações de frequência: a fonte alternativa deve possuir sistemas capazes de desconectá-la caso haja alterações na frequência fundamental da rede. Para uma fonte de até $30 \mathrm{~kW}$, com frequência nominal de $60 \mathrm{~Hz}$, o TS é de 0,16 s para extrapolação da frequência maior que $60,5 \mathrm{~Hz}$ ou menor que $59,3 \mathrm{~Hz}$.

- Harmônicos de corrente: ao alimentar cargas lineares, a distorção harmônica não deve ultrapassar 4\% para as harmônicas ímpares menores que 11, 2\% para as harmônicas entre 11 e 17, 1,5\% para as harmônicas entre 17 e 23, 0,6\% para as harmônicas entre 23 e 35 e 0,3\% para harmônicas ímpares maiores que 35. As harmônicas pares devem ser limitadas a $25 \%$ das ímpares para cada caso.

Levando-se em consideração toda teoria sobre aerogeradores de pequeno porte, bem como os elementos do sistema de interligação com a rede elétrica aqui exposta, e de posse das características principais do AGPP, é possível modelar esse equipamento de forma a retirar o máximo proveito de sua utilização em qualquer ambiente, com condições de vento favoráveis que necessite de geração elétrica. Além disso, ressalta-se 
a aplicação da tecnologia AGPP para o desenvolvimento de uma das vertentes da filosofia das redes inteligentes, que é a utilização de fontes alternativas em microgeração, norteando futuros trabalhos e projetos de pesquisas nos diversos setores do conhecimento que possam contribuir cientificamente para as áreas do estudo em questão, utilizando o potencial eólico em benefício dos consumidores de energia e da rede elétrica do país.

\section{Conclusões finais}

O uso de pequenos aerogeradores ainda não está totalmente consolidado. Esses equipamentos possuem baixo rendimento operacional em relação à capacidade de conversão da energia cinética dos ventos em energia elétrica. Além disso, seu custo ainda é elevado, dificultando a inserção da geração de energia elétrica por intermédio de pequenos aerogeradores. Entretanto, esses fatores devem ser superados com o desenvolvimento dessa tecnologia.

Com o domínio da tecnologia de aerogeradores de pequeno porte, através de simulações computacionais e modelagens, pode-se prever detalhadamente o desempenho do complexo eólico-elétrico dentro de uma gama variável de situações, como a relação direta entre as variações da velocidade do vento e o comportamento elétricomecânico do aerogerador. $\mathrm{O}$ avanço tecnológico mencionado poderá contribuir para a inserção definitiva da energia eólica distribuída no Brasil, reduzindo os problemas de consumo de energia elétrica, principalmente, aqueles em horários de pico, onde o sistema elétrico de potência opera, normalmente, com sobrecarrega. A geração distribuída seria, portanto, fundamental para manter o sistema de distribuição mais eficiente, do ponto de vista das perdas. Além disso, como é sabido, a produção de energia elétrica não acompanha continuamente o aumento do consumo.

Com este trabalho, espera-se abrir a possibilidade para debates que consolidem o uso de fontes alternativas de energia, principalmente a eólica, de forma a aproveitar esse recurso natural, presente em abundância em algumas regiões do país, devido a sua característica limpa e renovável, evitando o uso de fontes poluentes que apresentam elevados danos para o meio ambiente. Vale salientar que as regiões litorâneas e o Nordeste brasileiro seriam os locais mais favorecidos, visto que essas regiões apresentam 
as melhores condições de vento [16].

Espera-se, também, mostrar a viabilidade da tecnologia aqui relatada como participante ativa na filosofia das redes inteligentes ou smart grids através do processo de microgeração, uma vez que, como foi exposto, o futuro do sistema de geração e distribuição de energia elétrica está encaminhando para essa direção, na qual o consumidor passará a atuar ativamente no processo de geração, além de possuir pleno controle do seu consumo de energia elétrica.

\section{Agradecimentos}

Os autores agradecem a Fundação de Amparo à Pesquisa do Estado da Bahia FAPESB pelo apoio financeiro no fornecimento de uma bolsa de iniciação científica.

\section{Referências}

[1] DEBLASIO, R.; TOM, C. Standards for the smart grid. Energy 2030 Conference, Energy IEEE, p. 1-7, 2008.

[2] OLIVEIRA, L. N. Levantamento do estado da arte sobre smart grid. Trabalho de Conclusão de Curso, Engenharia Elétrica, UNIVASF, Juazeiro, Brasil, 2010.

[3] KNIGHT, P. T. Smart Grid - Redes elétricas inteligentes. Rev Banco Hoje, São Paulo, nov/2008. Colunistas, p.10. Disponível em http://www.tedbr.com/publicacoes/bancohoje2008/bancohoje11-08.htm. Acesso em ago/2011.

[4] AZZOPARDI, B.; MUTALE, J. Smart integration of future grid-connected PV systems. IEEE Potentials, Manchester, Jun/2009.

[5] CANAZIO, A. Redes Inteligentes: uma revolução na gestão do consumo. Disponível em http://www.procelinfo.com.br/data/Pages/LUMIS8D1AC2E8ITEMID5C19 B49396DD4B11BCD6DFC2CDC6FC73PTBRIE.htm. Acesso em jun/2011. 
[6] LEÃO, R. GTD - Geração, Transmissão e Distribuição de Energia Elétrica. Cap. 1, f. 40, 2010. Apostila para disciplina GTD - Geração, Transmissão e Distribuição de Energia Elétrica - Universidade Federal do Ceará - UFC-2010. Disponível em: http://www.dee.ufc.br/ ${ }^{\sim}$ rleao/GTD/I\%20Introducao.pdf. Acesso em set/2010.

[7] EPE - Empresa de Pesquisa Energética. Balanço Energético Nacional 2011 Ano base 2010: Resultados Preliminares. Rio de Janeiro, 2011.

[8] MANGAS, R. Redes de distribuição de energia com microgeração - Avaliação do impacto de diferentes condições de licenciamento. Dissertação de Mestrado, Faculdade de Engenharia da Universidade do Porto - FEUP. p. 112, 2009.

[9] GRANDIN, F. Microgeração eólica. Portal energia hoje, 01 de novembro 2011. Disponível em http://www.energiahoje.com/brasilenergia/noticiario/2011/11/01/441892/ microgeracao-eolica.html. Acesso em jan/2012.

[10] COSTA, L. Jornal da energia, 27 de setembro de 2011. Disponível em http://www.jornaldaenergia.com.br/ler_noticia.php?id_noticia=78168id_ tipo=3\&id_secao=9\&id_pai=2. Acesso em nov/2011.

[11] COSTA, L. Jornal da energia, 09 de agosto de 2011. Disponível em http://www.jornaldaenergia.com.br/ler_noticia.php?id_noticia=7297\&id tipo $=3 \&$ id_secao $=2$. Acesso em ago/2011.

[12] CANAZIO, A. Microgeração: um novo mercado. Agência Canal Energia, 28 de outubro de 2011. Disponível em http://www.gasnet.com.br/conteudo/12941. Acesso em jan/2011.

[13] ANEEL: Agência Nacional de Energia Elétrica. www.aneel.gov.br. Acesso em set $/ 2010$.

[14] SANTOS, A. Projeto de geração de energia eólica. Projeto de Conclusão do Curso de Engenharia Mecânica. Universidade de Santa Cecília. Santos, SP, 2006. 
[15] WINDPOWER, Monthly news magazine, [Knebel]: Windpower Monthly, v. 19, 2003. In: ANEEL: Agência Nacional de Energia Elétrica. Disponível em www.aneel.gov.br. Acesso em jan/2011.

[16] AMARANTE, O.; BROWER, M.; ZACK, J.; SÁ, A. L. Atlas do potencial eólico brasileiro, Camargo Schubert Engenharia Eólica, True Wind Solutions, Centro de Pesquisas de Energia Elétrica/CEPEL, Brasília, 2001.

[17] PATEL, M. Wind and Solar Power Systems, CRC Press LLC, New York - USA, $1^{a}$ ed., 1999.

[18] PINTO, A. C. Modelagem e análise de desempenho de complexos elétricos contendo centrais eólicas dotadas de geradores síncronos. Tese de Doutorado. Universidade Federal de Uberlândia, 2007.

[19] PLURIENERGIA LDA, Energia solar e eficiência energética, Disponível em http://www.plurienergia.pt/tecnologias-eolicas.html. Acesso em ago/2011.

[20] DAHER, F. A. Análise, simulação e implementação de um conversor de baixa potência com MPPT e PFC para aerogeradores em sistemas isolados. Dissertação de Mestrado. PUC - RS, 2006.

[21] ALDABÓ, R. Energia eólica, Artliber Editora, São Paulo, 2002.

[22] MARQUES, J. Turbinas Eólicas: modelos, análise e controle do gerador de indução com dupla alimentação. Dissertação de Mestrado, Universidade Federal de Santa Maria, 2004.

[23] CAMPOS, F. G. R. Geração de energia a partir de fonte eólica com gerador assíncrono conectado a conversor estático duplo. Dissertação de Mestrado, USP, São Paulo, 2004.

[24] MACCARINI, M. C. Inversor monofásico sincronizado para conexão de um gerador eólico à rede elétrica: Estudo, projeto e implementação. Dissertação de Mestrado, Universidade Federal de Santa Catarina, 2009. 
Revista Ciências Exatas e Naturais, Vol.14, n 1, Jan/Jun 2012

[25] FRIEDMAN, N. R. Distributed Energy Resources Interconnection Systems: Technology, Review and Research Needs. National Renewable Energy Laboratory, Virginia, USA, 2002. 